\title{
Leidt (bij)scholing van docenten tot beter onderwijs?
}

\author{
J. Wouda, R.R. Seton-Mulder, J. Cohen-Schotanus
}

\section{Samenvatting}

Inleiding: Probleemgestuurd onderwijs waarbij studenten in kleine groepen werken aan studietaken, is inmiddels een vertrouwde onderwijsvorm in vele medische curricula. De $k w a l i t e i t$ van de tutoren speelt een cruciale rol in het functioneren van deze tutorgroepen. Docenten worden meestal geschoold om de rol van tutor goed te kunnen vervullen. Uit de ervaringen in Groningen blijkt dat een eenmalige scholing geen garantie is voor het goed functioneren van de tutorgroepen. Extra inzet van de onderwijsorganisatie blijkt nodig om de kwaliteit van de tutoren op het gewenste peil te brengen en te houden. In Groningen is daarom in 1996 een project gestart om docenten beter voor te bereiden op en te begeleiden bij hun onderwijstaken.

Beschrijving: In eerste instantie heeft het project zich gericht op het beter vervullen van de tutorrol door middel van scholing en individuele feedback. Uit de evaluaties blijkt dat de tutoren en tutorgroepen inderdaad beter zijn gaan functioneren. In een volgende fase is ook aandacht besteed aan de docenten die verantwoordelijk zijn voor het maken van de studieopdrachten waarmee in de tutorgroepen gewerkt wordt. De kwaliteit hiervan nam in de loop der jaren eveneens toe dankzij de gerichte instructies en feedback. Hierdoor verbeterde eveneens de kwaliteit van het werken in de tutorgroepen.

Conclusie: Het blijkt dat scholing en feedback voor docenten kan leiden tot een beter functioneren van tutorgroepen, mits men zich niet alleen richt op de docenten die de tutorgroepen begeleiden, maar ook op de docenten die verantwoordelijk zijn voor het studiemateriaal waarmee in de tutorgroepen wordt gewerkt. (Wouda J, Seton-Mulder RR, Cohen-Schotanus $J$. Leidt (bij)scholing van docenten tot beter onderwijs? Tijdschrift voor Medisch Onderwijs 2001;20(6):241-247.)

\section{Inleiding}

Veel medische opleidingen zijn inmiddels overgegaan naar een studentgecentreerd curriculum met probleemgestuurd onderwijs als belangrijke onderwijsvorm. ${ }^{1-4}$ Probleemgestuurd onderwijs vereist een andere leeromgeving, een andere onderwijsorganisatie en ook andere docentenrollen dan een traditioneel curriculum. In traditionele curricula wordt van docenten vooral gevraagd om hun inhoudelijke deskundigheid over te dragen aan de studenten. In studentgecentreerde curricula treden docenten meer op als coach van het leerproces. In de meeste studentgecen- treerde curricula wordt gewerkt in kleine studiegroepen (tutorgroepen) en vervult de begeleider (tutor) een cruciale docentenrol. De tutoren begeleiden de studenten bij het actief verwerven van kennis en scheppen de voorwaarden voor dit leerproces. 5

Bij de omschakeling van een traditioneel curriculum naar een studentgecentreerd curriculum moeten de docenten worden voorbereid op hun nieuwe onderwijsrollen. Daarbij gaat het niet alleen om het vergroten van hun didactische competentie, maar ook om het versterken van hun motivatie voor het probleemgestuurd 
onderwijs. ${ }^{6-8}$ Deze omschakeling van docenten verloopt soms moeizaam. Tutorgroepen functioneren dan niet naar behoren en het leerproces van de studenten verloopt niet volgens plan. De onderwijsorganisatie dient zich vervolgens extra in te spannen om de docenten op het vereiste niveau te brengen en te houden.9-13 Het is echter de vraag of deze extra inspanningen om de kwaliteit van docenten te vergroten ook leiden tot een beter functioneren van de tutorgroepen. Dit artikel beschrijft de ervaringen met docententrainingen bij de medische faculteit te Groningen.

\section{Het curriculum in Groningen}

Het onderwijscurriculum C2000 van de Faculteit der Medische Wetenschappen in Groningen is een patiëntgeoriënteerd en probleemgestuurd onderwijsprogramma dat is opgedeeld in trimesters. ${ }^{14}$ De trimesters in de eerste drie studiejaren en het eerste trimester van het vierde studiejaar - in totaal tien trimesters - zijn opgebouwd uit twee à drie cursussen, die ieder weer bestaan uit een aantal 'modelweken'. Een modelweek bevat twee bijeenkomsten van de tutorgroepen, begeleid door een tutor. Iedere tutorgroep bestaat uit negen of tien studenten. Na ieder trimester worden de tutorgroepen opnieuw ingedeeld en door een nieuwe tutor begeleid. Een docent is per cursusjaar in het algemeen gedurende één trimester actief als tutor en begeleidt dan één of twee tutorgroepen.

Tijdens de eerste bijeenkomst wordt er gebrainstormd over de vier studieopdrachten van de week. Deze brainstorm resulteert in studievragen die de studenten in de loop van de week uitwerken en waarover ze aan elkaar rapporteren tijdens de tweede bijeenkomst van de tutorgroep.

Het onderwijsprogramma wordt aangestuurd door een centrale onderwijsorgani- satie. Docenten worden bijgeschoold voor hun nieuwe onderwijsrollen en alle programmaonderdelen worden systematisch geëvalueerd. Uit deze evaluaties bleek onder meer dat het werken in de tutorgroepen niet geheel volgens wens verliep. 1516 In 1996 is daarom een project gestart om docenten beter voor te bereiden op en te begeleiden bij het vervullen van hun onderwijstaken in het Groningse curriculum. ${ }^{17}$

\section{Interventies}

Het project 'Scholing en Omscholing Docenten' heeft zich in eerste instantie gericht op de rol van de tutor. In tweede instantie is ook aandacht besteed aan de constructeurs van de studieopdrachten.

\section{(Bij)scholing van en feedback aan tutoren}

Het werken in de tutorgroepen en de rol van de tutor in C2000 zijn goed omschreven. ${ }^{18} \mathrm{Op}$ basis van de omschrijving is een lijst met criteria vastgesteld waarmee het functioneren van de tutorgroepen en van de tutor kan worden beoordeeld. Deze criteria zijn onder meer gebruikt bij de observatie van negentig tutoren tijdens het begeleiden van een tutorgroep. Na iedere observatie kreeg de betreffende tutor feedback over het vervullen van de tutorrol.

Op basis van de beoordelingscriteria en de ervaringen elders is een vragenlijst ontwikkeld voor het evalueren van de tutorgroepen en de tutoren door de studenten. ${ }^{9}$ 121920 De constructie en afname van de vragenlijst worden hieronder besproken. De antwoorden van de studenten uit één tutorgroep werden samengevoegd en gebruikt voor feedback aan hun tutor over zijn/haar optreden. De evaluatiegegevens zijn ook gebruikt om het gewenste profiel van de tutor in C2000 vast te stellen. Met name is gekeken naar het belang van inhoudsdeskundigheid voor het kunnen functioneren als tutor in C2000. ${ }^{21}$ 
Uit de observatie- en evaluatiegegevens kwamen enkele algemene knelpunten in het functioneren van de tutorgroepen en tutoren naar voren. Op grond van deze bevindingen zijn voor het cursusjaar 1998/ 1999 een aantal procedures voor het werken in de tutorgroepen aangepast en is ook de bestaande tutortraining van twee dagen grondig herzien. Tevens is besloten om voorafgaand aan ieder trimester een instructiebijeenkomst voor tutoren te organiseren om hen te informeren over de aanpassingen in het onderwijs in de tutorgroepen en om hun kennis over de tutorgroepprocedures op te frissen.

\section{Verbeteren van de studieopdrachten}

De brainstorm over de vier studieopdrachten tijdens de eerste bijeenkomst van de tutorgroep is bedoeld om studenten te leren systematisch na te denken en te discussiëren over een (klinisch) probleem. De studieopdrachten dienen daarom breed te zijn geformuleerd en een aansprekend klinisch probleem te beschrijven. Een bevinding uit de observaties en evaluaties was dat de studieopdrachten vaak een onvoldoende prikkel waren voor een zinvolle brainstorm. ${ }^{22} \mathrm{Ze}$ waren te veel als 'opzoekvragen' geformuleerd. Het project is zich daarom gaan bezighouden met de constructeurs van deze studieopdrachten: de week- en cursuscoördinatoren.

Als eerste stap is vastgesteld wat de kenmerken zijn van een goede studieopdracht. Hierbij is gebruik gemaakt van ervaringen elders en van de evaluatiegegevens van de studieopdrachten door studenten en tutoren. ${ }^{23-28}$ Het maken van goede studieopdrachten werd in het cursusjaar 1998/1999 het thema voor een aantal workshops en individuele instructie voor de constructeurs. De kwaliteit van de studieopdrachten wordt sindsdien systematisch geëvalueerd. De resultaten van deze evaluaties worden telkens teruggekoppeld naar de betreffende constructeurs met aanwijzingen voor verdere verbetering.

\section{Evaluaties}

De effecten van de bovenbeschreven interventies zijn vastgesteld op basis van de volgende evaluatiegegevens uit de cursusjaren 1997/1998, 1998/1999 en 1999/2000:

- evaluatie van tutoren en tutorgroepen;

- evaluatie van de studieopdrachten;

- de cursusevaluaties.

\section{Evaluatie van tutoren en tutorgroepen}

De studenten geven na afloop van het mondeling examen aan het einde van ieder trimester een oordeel over hun tutor en over het werken in de tutorgroep. Hiertoe worden 27 stellingen aan hen voorgelegd. 25 van deze stellingen hebben betrekking op het gedrag van de tutor tijdens een tutorgroepbijeenkomst. De stellingen zijn positief geformuleerd. Studenten kunnen kiezen uit vier antwoordmogelijkheden: helemaal eens (4), grotendeels eens (3), grotendeels oneens (2) of helemaal oneens (1). Daarnaast wordt een algemeen oordeel gevraagd over het functioneren van de tutorgroep (vierpuntsschaal) en over het functioneren van de tutor (schoolcijfer 1-10). Uit een factoranalyse van de antwoorden van de studenten (varimaxrotatie) kwamen vier subschalen naar voren: 1. bewaken van de inhoudelijke kwaliteit van discussies en rapportages;

2. bewaken van het juiste verloop van de agendapunten, zoals de brainstorm, de rapportages en de feedbackprocedure;

3. corrigeren van het groepsproces en van het individueel functioneren van studenten, zoals spanningen in de groep, te laat komen of gebrek aan inzet tonen;

4. eigen houding tegenover de studenten en het werken in de tutorgroep, zoals enthousiasme tonen, bejegening van studenten en eigen inzet. ${ }^{21}$ 
De items behorende bij ieder van de vier subschalen zijn samengevoegd tot vier nieuwe variabelen. De scores op deze vier variabelen zijn omgezet in scores op een schaal van $0-10$.

\section{Evaluatie studieopdrachten}

Het effect van de interventies ter verbetering van de studieopdrachten kan worden opgemaakt uit twee informatiebronnen. De eerste bron is de evaluatie van de studieopdrachten, die vanaf het cursusjaar 1997/1998 plaatsvindt. Gedurende een cursus geven acht tot tien random geselecteerde tutorgroepen met een 'schoolcijfer' van 1-10 een oordeel over iedere studieopdracht uit de cursus. Zij geven tevens commentaar op de kwaliteit van enkele aspecten van de studieopdrachten, zoals over het brainstormen en over de rapportage.

De tweede informatiebron over de kwaliteit van de studieopdrachten zijn de cursusevaluaties aan het eind van iedere cursustoets. In deze vragenlijst zijn ook enkele uitspraken opgenomen over de studieopdrachten. Op een vierpuntsschaal ( 4 = helemaal eens; 3 = grotendeels eens; 2 = grotendeels oneens; 1 = helemaal oneens) geven de studenten aan in hoeverre ze het eens of oneens zijn met de volgende stellingen:
- de studieopdrachten nodigden uit tot brainstormen;

- het brainstormen leverde goede ideeën op voor de uitwerking van de studieopdrachten;

- de rapportages over de studieopdrachten boden een goede aanvulling op en verdieping van de leerstof.

\section{Resultaten}

\section{Evaluatie van tutoren en tutorgroepen}

In de drie cursusjaren 1997/1998, 1998/ 1999 en 1999/2000 is er in ( 3 x $10=)$ dertig trimesters onderwijs gegeven. In deze trimesters hebben 650 tutorgroepen gefunctioneerd, die werden begeleid door 548 tutoren (sommige tutoren begeleidden meer dan één groep). In totaal zijn er 5829 evaluaties over deze tutoren ontvangen, dat wil zeggen van gemiddeld bijna negen studenten per tutorgroep.

Tabel 1 toont de uitkomsten van de tutorevaluaties. Weergegeven staan de gemiddelde scores voor de vier subschalen (0-10), het oordeel over de tutor (rapportcijfer 1-10) en het algemene oordeel over het functioneren van de tutorgroepen (vierpuntsschaal 1-4) in de drie opeenvolgende cursusjaren. De verschillen

Tabel 1. Beoordeling van de tutoren door studenten. Voor de factoren 1 tot en met 4 en het schoolcijfer geldt een schaal van 0-10. Het functioneren van de tutorgroep is beoordeeld op een vierpuntsschaal (1-4).

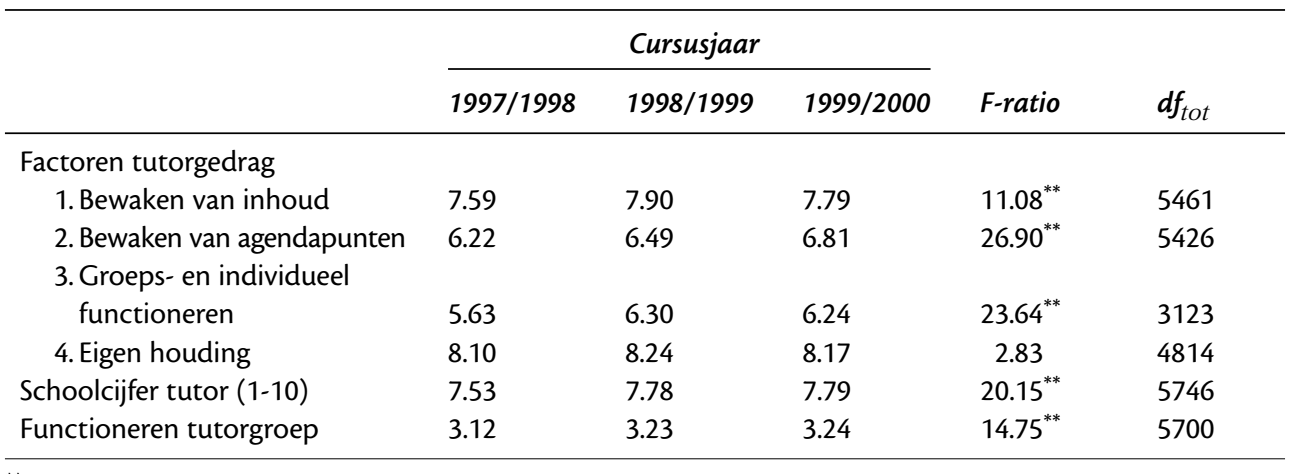

${ }^{* *} \mathrm{p}<.001$ 
tussen de scores uit de drie cursusjaren zijn getoetst door middel van een univariate variantieanalyse. In de één na laatste kolom staat de verkregen F-ratio en in de laatste kolom het totaal aantal vrijheidsgraden van deze F-ratio. Een significante F-ratio $(\mathrm{p}<.001)$ is aangegeven met ${ }^{* *}$.

De tabel laat zien dat in de loop van de drie cursusjaren de beoordelingen voor de subschalen 1. inhoud; 2. procedure en 3. groeps- en individueel functioneren positiever worden. De sterkste toename vindt plaats in het cursusjaar 1998/1999 en vooral voor de subschalen 2 en 3. De beoordeling voor subschaal 4 , de eigen houding van de tutor, is niet significant verschillend over de drie cursusjaren.

Het algemene oordeel over de tutorgroep en het rapportcijfer voor de tutoren vertonen eveneens een stijgende lijn. Ook hierbij treedt de sterkste stijging op in 1998/ 1999 en vindt er een stabilisatie plaats in het derde cursusjaar.

\section{Evaluatie studieopdrachten}

Gedurende de drie cursusjaren zijn in totaal 5815 evaluaties ontvangen over 944 studieopdrachten. Dit is gemiddeld 6.16 tutorgroepoordelen per studieopdracht. Tabel 2 laat het gemiddelde schoolcijfer zien voor deze studieopdrachten over de drie cursusjaren.
De tabel laat zien dat de studieopdrachten in het algemeen met een voldoende worden beoordeeld: gemiddelde cijfer tussen 6.74 en 6.92 . Uit een univariate variantieanalyse blijkt dat de waardering over de cursusjaren toeneemt, met de sterkste toename voor het cursusjaar 1999/2000.

Tabel 2 toont tevens de resultaten uit de cursusevaluaties over de beoordeling van (het werken met) de studieopdrachten in de tutorgroepen. In de drie cursusjaren zijn er in totaal 75 cursussen geweest. Hierover zijn 11779 vragenlijsten ingevuld. Dat is gemiddeld 157 respondenten per cursus. De tabel laat zien dat het werken met de studieopdrachten in de loop der cursusjaren is verbeterd. De sterkste verbetering treedt op voor het studiejaar 1998/1999. In 1999/2000 treedt een stabilisatie op.

\section{Discussie en conclusie}

Het project 'Scholing en Omscholing Docenten' had tot doel de docenten van de medische faculteit beter voor te bereiden op en te begeleiden bij het uitvoeren van hun onderwijstaken. Uit de evaluatieresultaten blijkt dat in de loop van de projectperiode de tutoren en tutorgroepen beter zijn gaan functioneren. De beschreven interventies hebben blijkbaar effect gehad. De bereikte verbeteringen kunnen echter niet alleen worden toegeschreven

Tabel 2. Beoordeling door de studenten van de studieopdrachten: een schoolcijfer (1-10) en beoordelingen op een vierpuntsschaal (1-4).

\begin{tabular}{llllll}
\hline & \multicolumn{3}{c}{ Cursusjaar } & & \\
\cline { 2 - 4 } & $1997 / 1998$ & $1998 / 1999$ & $1999 / 2000$ & F-ratio & $d f$ \\
\hline $\begin{array}{l}\text { Schoolcijfer studieopdrachten } \\
\text { Kwaliteit studieopdrachten }\end{array}$ & 6.74 & 6.75 & 6.92 & $15.00^{* *}$ & 5815 \\
- zijn uitnodigend & 2.58 & 2.68 & 2.70 & $22.04^{* *}$ & 11276 \\
- goede brainstorm & 2.63 & 2.78 & 2.82 & $60.00^{* *}$ & 11042 \\
- goede rapportages & 2.94 & 3.04 & 3.02 & $16.53^{* *}$ & 11203 \\
\hline ** & & & & &
\end{tabular}


aan deze interventies. Tijdens de projectperiode heeft het verbeteren van het onderwijs ook op andere manieren aandacht gekregen. Zo zijn er enkele regels rond de examinering veranderd, wat tot gevolg had dat de relevantie van het werken in de tutorgroepen voor de studenten duidelijker is geworden. Ook hebben de bevindingen in de eerste fase van het project geleid tot aanpassingen in het werken in de tutorgroepen. Beide veranderingen hebben er waarschijnlijk mede toe geleid dat de tutorgroepen beter zijn gaan functioneren.

Anderzijds blijkt uit de evaluaties dat de tutoren vooral zijn verbeterd in hun optreden als procesbegeleider (subschalen 2 en 3). Juist op dit aspect van hun taak is in de (bij)scholingen extra de nadruk gelegd. Ook de interventies ter verbetering van de studieopdrachten waren vrij specifiek, zodat de waargenomen verbeteringen grotendeels hieraan kunnen worden toegeschreven. De voorzichtige conclusie kan daarom worden getrokken dat de volgende interventies effectief zijn geweest om het functioneren van tutoren en tutorgroepen in een probleemgestuurd curriculum te verbeteren:

- zorgen voor een duidelijke en gedetailleerde beschrijving van de werkwijze in de tutorgroepen en van de taken van de tutor;

- aanpassing van deze procedures en taken op grond van evaluaties;

- observatie van tutoren 'on the job' met feedback;

- systematische feedback op basis van studentevaluaties;

- regelmatige opfrismomenten om tutoren te informeren over aanpassingen in het curriculum en in hun taken;

- bijscholing van en feedback voor de constructeurs van het onderwijsmateriaal waarmee wordt gewerkt in de tutorgroepen.
Het laatste punt is van groot belang. Als men tutorgroepen goed wil laten functioneren, dan is men wellicht geneigd om de scholingsaandacht vooral te richten op de tutoren. Het welslagen van de tutorgroepen is echter ook sterk afhankelijk van allerlei randvoorwaarden zoals het onderwijsmateriaal. Docenten met een construerende en coördinerende rol dienen daarom eveneens te worden voorzien van duidelijke richtlijnen voor de constructie van hun onderwijsmateriaal en van feedback over de kwaliteit van hun producten. Ontbreekt dit onderdeel van de (bij)scholing, dan is zelfs de best geschoolde tutor niet bij machte om in de tutorgroep het proces van probleemgestuurd leren naar wens te laten verlopen.

\section{Literatuur}

1. Bouhuijs PAJ, Schmidt HG, Berkel HJM van. Problem-based learning as an educational strategy. Maastricht: Network Publications; 1993.

2. Wood EJ. The problems of problem-based learning. Biochemical Education 1994;22:78-82.

3. Dolmans D, Wolfhagen I, Vleuten $\mathrm{C}$ van der, Wijnen W. Wanneer is onderwijs studentgecentreerd? Medisch Contact 1997;52:1045-7.

4. Maudsley G. Do we all mean the same thing by 'Problem-based learning'? A review of the concepts and a formulation of the ground rules. Acad Med 1999;74:178-85.

5. Grave WS de, Dolmans DHJM, Vleuten CPM van der. Profiles of effective tutors in problem-based learning: scaffolding student learning. Med Educ 1999;33:901-6.

6. Finucaine P, Allerly LA, Hayes TM. Comparison of teachers at a 'traditional' and an 'innovative' medical school. Med Educ 1995;29:104-9.

7. Evans PA, Taylor DCM. Staff development of tutor skills for problem-based learning. Med Educ 1996;30:365-6.

8. Wetzel MS. Developing the role of tutor/facilitator. Journal of Postgraduate Medicine 1996;72:474-7.

9. Dolmans DHJM, Wolfhagen HAP, SnellenBalendong HAM. Improving the effectiveness of tutors in problem-based learning. Med Teacher 1994;16:369-77.

10. Holmes DB, Kaufman DM. Tutoring in problembased learning: a teacher development process. Med Educ 1994;28:275-83.

12. Des Marchais JE, Chaput M. A comprehensive continuous preclinical PBL tutor training system. Teaching and Learning in Medicine 1997;9:66-72. 
13. White PT, Stephenson AE. Supervised teaching practice: a system for teacher support and quality assurance. Med Teacher 2000;22:604-6.

14. Rossum HJM van, Wijnands L, Meijer K. Curriculum 2000: patiëntgeoriënteerd onderwijs aan de medische faculteit Groningen. Ned Tijdschr Geneeskd 1994;138:1184-7.

15. Seton-Mulder RR, Wouda J, Cohen-Schotanus J. Van een traditioneel naar een patiëntgeoriënteerd curriculum: veranderen docenten mee? In: Verweij AMJJ, Albersnagel EA, Cate ThJ ten, Denekens J, Dikkers JH, Remmen R, et al. Gezond Onderwijs 7. Houten/Diegem: Bohn Stafleu Van Loghum; 1998. p. 269-271.

16. Wouda J, Seton-Mulder RR, Cohen-Schotanus J. Van een traditioneel naar een patiëntgeoriënteerd curriculum: wie bepalen het succes van het onderwijs in tutorgroepen? In: Verweij AMJJ, Albersnagel EA, Cate ThJ ten, Denekens J, Dikkers JH, Remmen R, et al. Gezond Onderwijs 7. Houten/Diegem: Bohn Stafleu Van Loghum; 1998. p. 339-341.

17. Wouda J. Scholing en omscholing, de effectieve docent in een studentgecentreerd curriculum. In: Hokwerda $\mathrm{O}$ et al., redactie. Een duwtje in de rug. Groningen: Rijksuniversiteit Groningen; 2000. p. 142-165.

18. Wouda J. Studeren in een tutorgroep. Groningen: Faculteit Geneeskunde; 1999 (5e druk).

19. Grave WS de, Dolmans DHJM, Vleuten CPM van der. Tutor intervention profile: reliability and validity. Med Educ 1998;32:262-8.

20. Seton-Mulder RR, Wouda J, Rossum HJM van, Zwierstra RP, Cohen-Schotanus J. Patiëntgeoriënteerd onderwijs: De ontwikkeling van een evaluatielijst voor tutoren. In: Spaai GWG, Verweij AMJJ, Remmer R, Dolmans DHJM, Denekens JPM, Smal JA, et al. Gezond Onderwijs 8. Houten/Diegem: Bohn Stafleu Van Loghum; 1999. p. 275-278.

21. Seton-Mulder RR, Agsteribbe J, Wouda J, CohenSchotanus J. Patiëntgeoriënteerd onderwijs: Verschillen tussen arts-tutoren en niet-arts-tutoren. In: Spaai GWG, Verweij AMJJ, Remmen R,
Dolmans DHJM, Denekens JPM, Smal JA, et al. Gezond Onderwijs 8. Houten/Diegem: Bohn Stafleu Van Loghum; 1999. p. 270-274.

22. Wouda J, Seton-Mulder RR, Cohen-Schotanus J. Een patiëntgeoriënteerd curriculum: Welke studieopdrachten werken het beste? In: Spaai GWG, Verweij AMJJ, Albersnagel EA, Cate ThJ ten, Denekens J, Dikkers JH, Remmen R, et al. Gezond Onderwijs 8. Houten: Bohn Stafleu Van Loghum; 1999. p. 354-356.

23. Dolmans DHJM. How students learn in a problem-based curriculum [proefschrift]. Maastricht: Rijksuniversiteit Limburg; 1994.

24. Dolmans D, Snellen-Balendong H. Constructie van taken. Maastricht: Vakgroep Onderwijsontwikkeling en -research, Rijksuniversiteit Limburg; 1995.

25. Glick TH, Armstrong EG. Crafting cases for problem-based learning: experience in a neuroscience course. Med Educ 1996;30:24-30.

26. Jayawickramarajah PT. Problems for problembased learning: a comparative study of documents. Med Educ 1996;30:272-82.

27. Mpofu DJS, Das M, Murdoch JC, Lanphear JH. Effectiveness of problems used in problem-based learning. Med Educ 1997;31:330-4.

28. Des Marchais JE. A Delphi technique to identify and evaluate criteria for construction of PBL problems. Med Educ 1999;33:504-8.

De auteurs:

drs. J. Wouda is docent-trainer

drs. R.R. Seton-Mulder is evaluator

Dr. J. Cohen-Schotanus, is hoofd van de afdeling Onderwijsontwikkeling en -kwaliteitszorg.

Allen zijn verbonden aan het Onderwijsinstituut van de Faculteit der Medische Wetenschappen van de Rijksuniversiteit Groningen.

Correspondentieadres:

J. Wouda, Medische Psychologie, Academisch Ziekenhuis Groningen, postbus 30002, 9700 RB Groningen tel: 050-3612045,j.c.wouda@medps.azg.nl.

\section{Summary}

Introduction: Problem-based learning in small groups is a prominent educational format in most student-centred medical curricula. The role of the teacher as group facilitator (tutor) is crucial in accomplishing the educational goals in problem-based learning. Teachers are usually prepared for this role by a teacher training programme. The experiences at the medical school in Groningen show that one training session is not sufficient. The educational department had to put more effort into enhancing the quality of the performance of the tutors and the tutorial groups. In 1996 a project was started aimed at improving the performance of tutorial groups. Initially, the focus was on the role of the tutor.

Description: Teachers were offered a programme of additional training and individual feedback. Evaluation of these interventions shows an improvement in the performance of the tutors and the tutorial groups over the years. Especially the group facilitating skills of the tutors improved. In the following phase of the project the teachers who are responsible for the production of the study tasks with which the tutorial groups work, were also targeted. These teachers participated in a course in constructing study tasks combined with individual feedback based on the evaluation of their study tasks. As a result the quality of the study tasks improved, which has contributed to the better functioning of the tutorial groups. Conclusion: Training and feedback for teachers was found to improve the functioning of the tutorial groups. It is important that training is not only aimed at the tutors, but also at the teachers who produce the study tasks. (Wouda J, Seton-Mulder RR, Cohen-Schotanus J. Does training of teachers improve learning in tutorial groups? Dutch Journal of Medical Education 2001;20(6):241-247.) 